\title{
A Ribbon of Glass on a River of Tin
}

When Alistair Pilkington (1920-1995) addressed the Royal Society of London on February 13, 1969, on "The Float Glass Process," he began with a brief history of glass in human affairs. After describing the shaping of glass into useful forms by ancient civilizations, Pilkington asked his audience's permission to jump forward in time. "Since it is with flat glass that my lecture is concerned," he said, "I hope you will therefore forgive me for skipping 3,000 years of history." For it was only ten years before, in 1959, after seven years of experimentation and an investment of $£ 7$ million, that Pilkington Brothers Ltd. of St. Helens, Lancashire, introduced an economical means of producing distortion-free flat glass that required no grinding or polishing steps.

That it took thousands of years to solve the problem of making truly flat glass is a testament to the difficulty of the challenge. There were several processes that produced useful approximations along the way: the "crown glass" method, which involved spinning a lump of molten glass rapidly until it cooled in a flat disk; the cylinder method, in which a blown cylinder of glass was cut lengthwise and opened into a flat sheet; and the Fourcault method, which involved drawing a continuous ribbon from a pool of molten glass. Though useful, each of these methods yielded glass with optical distortions.

An alternative was plate glass, in which molten glass was cast on a table, rolled into a plate, annealed, and then ground and polished to a flat, distortion-free finish. Though the result was excellent and an automated continuous process was developed in the early 1900s, polishing and grinding were expensive and wasted as much as $20 \%$ of the product.

Pilkington, a mechanical engineer and cousin of the Pilkington Brothers, whose company had been manufacturing glass since 1826, sought to combine the low cost of the sheet process with the optical quality of the plate process. In 1952, while working as the production manager in the plate glass department, he came up with the idea of using a flat surface of molten metal to support a continuous ribbon of glass. Because a molten metal surface is "dead flat," in Pilkington's words, the glass would also be flat. "When we started [experimenting]," he said, "we knew that what we were attempting was going to be one of the most exciting things in the history of the flat glass industry if we could pull it off."

The metal to be used had to be liquid over the temperature range of $600-1050^{\circ} \mathrm{C}$, the processing range of the glass. This narrowed the candidates to seven: bismuth, gallium, indium, lithium, lead, thallium, and tin. Lithium is not dense enough to support a glass ribbon, while bismuth, thallium, and lead would evaporate at $1050^{\circ} \mathrm{C}$. Of the remaining three choices, tin was cheap and readily available. In 1953 Pilkington filed a patent application titled "Float glass: Using a bath of molten tin to make plate glass cheaply."

That it took thousands of years
to solve the problem of making
truly flat glass is a testament to
the difficulty of the challenge.

But many technical and operational challenges lay ahead. Pilkington highlighted some of the challenges his team overcame, including regulating the chemistry of the tin-glass interface and controlling glass flow.

"We knew that under certain conditions glass and metal could live together," Pilkington said. Finding and controlling those conditions was the challenge. Tin reacts readily with any oxygen or sulfur present, and there were ample sources of both. The molten glass flowing from the furnace contained dissolved oxygen and sulfur, and the tin also contained both contaminants on the parts-per-million level. Stannous oxide and stannous sulfide evaporated into the atmosphere and would condense onto the top surface of the glass ribbon, leaving tin compounds called "top speck" on the surface. Furthermore, oxygen promoted the dissolution of tin into the glass melt. Eventually, the researchers solved the oxidation problem by sealing the compartment around the molten glass with a reducing atmosphere of nitrogen and hydrogen. They minimized sulfide contamination by controlling the flow and condensation patterns of stannous sulfide vapor.

Mastering glass ribbon formation involved controlling the thickness of the glass. Pilkington said that his team was surprised to find that no matter what thickness they started with, "we obtained a ribbon of final thickness close to $6 \mathrm{~mm}$ if the glass were held at a high enough temperature for a long enough time to melt out the irregularities." After careful consideration, they realized that the 6-mm thickness was dictated by gravity and surface tension. Fortunately for Pilkington
Brothers, about half the product the company supplied was already specified at approximately $6 \mathrm{~mm}$. After much experimenting, the researchers found that they could make panes as thin as $3 \mathrm{~mm}$ by applying tension to the glass while it floated on the tin bath, and as thick as $15 \mathrm{~mm}$ by slowing down the flow of the glass and allowing it to build up between two confining guide bars parallel to the sides of the bath.

Having overcome these and many more technical barriers, in 1959 Pilkington Brothers announced to the world the availability of flat glass using the "Pilkington Float Glass Process." Pilkington described the process that resulted from what he called "a terrific fight" of seven years of experimentation:

A stream of molten glass several centimeters thick is supplied continuously on to the surface of a bath of molten tin, and under the influence of the gravitational, surface tensional, and applied tractive [sic] forces...a continuous ribbon of glass is produced. For a normal soda-lime-silica glass it is necessary to maintain a temperature of $1050^{\circ} \mathrm{C}$...for approximately $1 \mathrm{~min}$ to produce a surface of the required degree of perfection.... As the ribbon is advanced along the bath it is progressively cooled. At a temperature of $600^{\circ} \mathrm{C}$ the viscosity is sufficiently high...for the ribbon to be removed mechanically from the bath without surface damage.

By 1969, the Pilkington Brothers had licensed the technology to 15 overseas glass manufacturers; together, they were producing about $100 \mathrm{~km}^{2}$ of glass per year. Today, approximately $90 \%$ of all plate glass is made using the Pilkington process.

Alistair Pilkington was named a Fellow of the Royal Society in 1969 for his scientific contributions and was knighted in 1970.

TIM PALUCKA

FOR FURTHER READING: Alistair Pilkington, "The Float Glass Process," Proceedings of the Royal Society of London A. 314 (1969) pp. 1-25; Christopher Layton, Christopher Harlow, and Charles de Hoghton, Ten Innovations (Crane, Russak \& Company, New York, 1972); Stephen van Dulken, Inventing the 20th Century: 100 Inventions that Shaped the World (The British Library, London, 2000); and Charles John Phillips, Glass, Its Industrial Applications (Reinhold Publishing Corp., New York, 1960). 